\title{
The Effect of Smoking on Adolescents' Appetite for the Age (13-18) and its Relationship to Some Variables
}

\author{
Eman Ali Hadi ${ }^{1}$, Fatima Faiq Juma ${ }^{1}$ \\ ${ }^{1}$ Scholar Researchers, University of Baghdad, Iraq
}

\begin{abstract}
Nutritional requirements increase for people in general and for adolescents in particular between the ages of (13-18) years to increase the speed of growth, as adolescence is considered a rapid stage after childhood. In general, the importance and necessity of nutritional elements remain, as they affect the growth of the teenager's body, so the amount of food that the teenager eats should be increased in proportion to his nutritional needs for this stage, however during this stage, he may be exposed to some practices related to the dietary approach and among these practices smoking, so the aim of the research is to identify the effect of smoking on the nutrition of male adolescents aged (13-18) years and its relationship to some variables, the results indicated a decrease in the average of the daily intake of a teenager smoker of age (13-15) and (15-18) of all proteins, carbohydrates, energy, vitamin B12, B6, E, C, A, folic acid, iron, calcium and phosphorous, respectively for smokers adolescents aged (15-13) years, while the rates of these elements were high among non-smoking adolescents for the same age group when compared with global courses. It was also observed through the results, the continued failure to meet the prescribed daily need for these nutrients for adolescent smokers aged 15-18 years, as the levels of nutrients reached, respectively, while the rates of these elements were reached in non-smoking adolescents for the same category, The statistics of the World Health Organization for the year 2008 indicated that smoking is more prevalent among adolescents aged (13-15) and (15-18) years for both sexes. Yemen was the first in the world and Kuwait in the Gulf in terms of youth smoking.
\end{abstract}

Keywords: smoking, adolescents'appetite, age 13-18

\section{Introduction}

Biologists (life scientists) use the ancient use of the term (adolescence) to mean the period from puberty to the end of sexual development. Many studies gathered on the behavior of adolescents began in the year 1795 and were characterized by scientific organization. Other scholars have defined it as period between childhood and adulthood during which sexual development is significant or during which developments in food habits and behavior are observed ${ }^{(1,2)}$. Some practices related to the adolescent's dietary approach appear at this stage $\mathrm{e}^{(3)}$. Smoking cigarettes, drinking alcohol or using drugs are pathological behaviors that often begin during this stage, it has a psychological and social impact, smoking is usually harmful and dangerous to health, and whether the nutrition of the adolescent at this stage is good or not, it depends on the factors surrounding him in addition to the independence that is related to cultural development and social level ${ }^{(3,4)}$. Adolescence is characterized by an increase in appetite for food with an increase in the rate of growth accompanied by an increase in energy spent daily. This may lead to an increase in food intake, and nutritionists defined appetite as a desire to eat, not the process of eating itself, and an increase in adolescents' appetite may result in the acceptance of many new foods that were previously rejected, as well as an increase in the quantities consumed by traditional foods ${ }^{(1)}$. In general, the nutritional requirements of adolescents between 13-18 years increase with the increase in their growth speed, but the teenager may be exposed to different types of nutritional problems. Various studies in the United States of America have indicated that most of the deficiency is in protein and energy, as well as in vitamin $\mathrm{A}, \mathrm{C}$, calcium and iron, so the skin is pale, hair is low in vitality, eyes lack luster, vitality decreases, and the chances of diseases such as anemia increase, which is 
one of the diseases prevalent among adolescents, as well as low weight, weak body resistance and intolerance to stress, so nutrition at this stage is very important due to the great need for additional quantities of the necessary elements to cause many changes, in order an adolescent becomes adult $(4,5,6)$.

\section{Materials and Methods}

To achieve the goal of the current study, a questionnaire form was prepared and included information on:

1- The profession of the parents.

2- Parents' educational attainment and the educational stage of adolescents.

3- The economic situation.

4- Number of family.

5- Eating daily breakfast on a regular basis.

6- Daily dietary curriculum.

The questionnaire also included questions specific to the teenager himself and the motives that prompted him to smoke:

1- The influence of the media.

2- The influence of friends and their imitation.

3- Absence of parents

4- Failure to study.

5- Escape from reality.

6- The desire to smoke

7- Parents and teachers imitation.

8- The economic factor.

9- Arranging the (adolescent) in his family.

10- Number of family.

The questionnaires were distributed to (1000) adolescents in the city of Baghdad on both sides of ALKarkh and AL-Rusafa, the randomized,

\section{Results and Discussion}

The study showed the following results:

First: Parents' profession: the percentage is in order from highest to lowest.

A- The profession of the father:

1- Employed: 65\%.

2- Freelancers: $35 \%$.

B- Mother's profession:

1- Employed: 55\%.

2- A teacher: $35 \%$.

3- Housewife: $10 \%$.

Second: Parents' Academic Achievement: The percentages are in order from highest to lowest:

1- Bachelor: $25 \%$.

2- High school: $25 \%$.

3- Institute (diploma): 16\%.

4- Middle school: 15\%.

5- Reads and writes: $14 \%$.

6- Illiterate: $5 \%$.

Third: Adolescent Academic Achievement:

The number of adolescents who are still continuing in middle and high school is $56 \%$.

As for adolescents who dropped out of school, their percentage was $35 \%$.

Fourth: The economic situation: The average monthly income of the family has reached ( 750 thousand Iraqi dinars).

Fifth: The number of family members: The general average is 6 members.

Sixth: As for breakfast, the percentage of adolescents who do not have daily breakfast was $55 \%$.

The remaining $45 \%$ are those who have breakfast. 
Sixth: The most common types of smoked cigarettes by (the research sample) are:

1- ASPEN 45\%. Its price is 750 Iraqi dinars.

2- PINE 37\%. Its price is 500 Iraqi dinars.
3- GAULOISES $18 \%$. Its price is 750 Iraqi dinars.

Eighth: As for the reasons or motives that prompted the teenager to smoke, they were shown in the following table:

Table (1) shows the motives that prompted the teenager to smoke, ranking them from highest to lowest

\begin{tabular}{|c|c|c|c|}
\hline Sequence & Motives and Causes & Figure & Percentage \\
\hline 1 & The influence of friends & 203 &, $20 \% 3$ \\
\hline 2 & A desire to smoke (or curiosity) & 192 & $2,19 \%$ \\
\hline 3 & Imitation of parents or teachers & 151 & $115 \%$ \\
\hline 4 & The economic factor & 95 & $5,9 \%$ \\
\hline 5 & Absence of a watcher (parents or one of them) & 89 & $9,8 \%$ \\
\hline 6 & Media influence & 70 & $7 \%$ \\
\hline 7 & Escape from reality & 58 & $6,8 \%$ \\
\hline 8 & Teenager's ranking in his family & 45 & $5,5 \%$ \\
\hline 9 & Number of individuals of the family & 32 & $4,5 \%$ \\
\hline 10 & Failure to study & 1000 & $3,2 \%$ \\
\hline
\end{tabular}

In Table (1) we notice that the first reason behind teenage smoking was the influence of friends, as it occupied the highest percentage, which is $20,3 \%$, and this comes with agreement with ${ }^{(1)}$, where it indicated that the highest percentage of smokers was $78 \%$, who they belong to centers and clubs or those who are in the same age or school stage, which gives indicative evidence that the group affects the behavior of the individual and his attitudes, so he imitates the group, and there is no awareness of the risks that this tradition entails on health.

In the same previous table, we also note that desire or curiosity ranked second after the influence of friends, with a rate of $19.2 \%$. The result of the research in this is consistent with ${ }^{(7)}$ as the first time to smoke is a result of a desire or love of curiosity, and this desire often comes from a friend or relative and this desire is repeated until the adolescent reaches the stage of addiction, the interpretation of this situation by psychologists is that desire is a pathological impulsion due to the smoker's need to obtain something that includes a sense of security and assertion of $\operatorname{self}^{(7)}$.

As for the third place, it was from the share of imitation of parents or teachers, it got a rate of $15.1 \%$, as the teenager at this stage accepts imitation of someone who is older than him, so he imitates his father or teacher, therefor parents and educators must set an example and quit smoking before they ask their children to do so. Studies have shown that many children refuse to respond to health awareness campaigns, believing that it is based on lying and deception, and they infer that from the father who forbids his children from smoking while he still smokes or from the doctor who advises his patient not to smoke while the cigarette is still burning between his fingers ${ }^{(1,8)}$.

While the economic factor ranked fourth, where it got a rate of $9.5 \%$, meaning that the higher the economic 
level, the greater the opportunity for the teenager to obtain his daily expenses, which in turn leads to spending this money on buying cigarettes without awareness from $\operatorname{him}^{(1,7)}$. As for the absence of a watcher (parents or one of them), it ranked fifth and obtained a rate of $8.9 \%$. The loss of parental or maternal care, or both, leads to this phenomenon (smoking), the absence of parents or one of them, or the family's preoccupation far from its children, is a major cause of children's delinquency, and it is called the "absent family", the later may be absent from the home or has no connection in this family. As for the influence of the media, the rate was $7 \%$. The media is considered a wide field for a daily confrontation between education and food awareness programs and commercial advertisements aimed at promoting food and non-food commodities, especially cigarettes (9), a teenager who watches TV for several hours a day is exposed to a large group of commercial advertisements that mainly focus on encouraging the consumption of a wide variety of cigarettes ${ }^{(10)}$. As for escaping from reality, it ranked seventh and obtained a rate of $6.8 \%$ by the research sample. A study conducted in the Arab Gulf states, specifically in Kuwait, revealed that most smokers were suffering from a change in behavior, ${ }^{(11)}$.
We note in the same table that the teenager's ranking in his family and the number of individuals of the family occupied the eighth and ninth positions, and their percentage was $5.5 \%$ and $4.5 \%$, respectively, according to the opinion of the members of the research sample. We conclude from this that children (adolescents suffer from the enormous number of family members), among the children of a family in which the number of members exceeds $9,51 \%$ of its children will be a smoker persons, and this percentage decreases as the number of family members decreases ${ }^{(10)}$.

In a family that consists from 7 or 8 members, the percentage of smokers among its children is less than $25.4 \%$, and for a family whose number is between 5 and 6 members, the percentage of young smokers (adolescents) approaches 20\%, meaning that the more family members the more increasing in the number of young smokers. Finally, failure to study, as it was ranked tenth and obtained a rate of $3.2 \%$, and this paragraph is part of the changes in the behavior of the teenager, as the teenager who smokes at this stage suffers from several difficulties, and among these difficulties is his inability to continue his studies, which leads to failure in his studies ${ }^{(11)}$.

Table (2) R.D.A global daily nutritional comparison with the average of daily intake of nutrients for smoker and non-smoker adolescents aged (13-15)

\begin{tabular}{|c|c|c|c|c|}
\hline sequence & Nutrients & $\begin{array}{c}\text { Global } \\
\text { Courses }\end{array}$ & $\begin{array}{c}\text { The general rate of } \\
\text { smoker adolescents } \\
\text { aged (13-15 years) }\end{array}$ & $\begin{array}{c}\text { The general rate } \\
\text { for non- smokers } \\
\text { adolescents aged } \\
\text { (13-15) }\end{array}$ \\
\hline 1 & Proteins (gm) & 52 & 40 & 54 \\
\hline 2 & Carbohydrates (g) & 130 & 122.3 & 132 \\
\hline 3 & Energy (calories) & 2700 & 2541 & 2729 \\
\hline 4 & V. A equivalent to Renol & 1000 & 887 & 1021 \\
\hline 5 & V. C mg & 50 & 39 & 59 \\
\hline 6 & V. B6 mg & 18 & 5.9 & 3.6 \\
\hline 7 & V. B12 mg & 305 & 2.2 & 14.5 \\
\hline 8 & Iron mg & 15 & 12.3 & 1212 \\
\hline 9 & Calcium mg & 1200 & 1089 & 1227 \\
\hline 10 & Phosphorous mg & 1200 & 1102 & 2 \\
\hline
\end{tabular}


Scheduled according to the National Food and Nutrition Science Recommendations for the Year (2002). (12)

Table (3) R.D.A global daily nutritional comparison with the average of daily intake of nutrients for smoker and non-smoker adolescents aged (16-18 years).

\begin{tabular}{|c|c|c|c|c|}
\hline sequence & Nutrients & Global & $\begin{array}{c}\text { The general } \\
\text { rate of smokers } \\
\text { adolescents aged } \\
\text { (16-18 years) }\end{array}$ & $\begin{array}{c}\text { The general rate } \\
\text { of non-smokers } \\
\text { adolescents aged } \\
\text { (16-18) years }\end{array}$ \\
\hline 1 & Proteins (gm) & 56 & 51 & 5.8 \\
\hline 2 & Carbohydrates (g) & 130 & 125 & 137 \\
\hline 3 & Energy (calories) & 3000 & 2678 & 2835 \\
\hline 4 & V. A equivalent to Renol & 1000 & 980 & 1015 \\
\hline 5 & V. C mg & 60 & 45 & 77 \\
\hline 6 & V. B6 mg & 2.0 & 1.3 & 2.4 \\
\hline 7 & V. B12 mg & 3.0 & 2 & 3.1 \\
\hline 8 & Iron mg & 15 & 12 & 19 \\
\hline 9 & Calcium mg & 1200 & 1160 & 1235 \\
\hline 10 & Phosphorous mg & 1200 & 1155 & 1228 \\
\hline
\end{tabular}

Scheduled according to the National Food and Nutrition Science Recommendations for the Year (2002). (12)

As for tables $(2,3)$, we note that the diet for adolescents for the age groups (15-13) and (18-16) generally suffers from a deficiency in the necessary nutrients. This is what we notice when comparing international courses. The teenager does not link food and body work, and much more of adolescents never think of disease, especially malnutrition, caused by loss of appetite as a result of smoking habit. At this stage (adolescence) the need for proteins, carbohydrates and energy increases, in order to balance the building of the body with the performance of daily moving activities ${ }^{(4)}$.

However, we note in the two tables that the quantities of these elements are low, as it was among adolescents who smoke at the age of (15-13), (44) grams, (122.3) grams, (2553) calories, respectively, and among adolescents who smoke at the age of (15-18), (5)
G, (125) gm and (2678) calories, respectively.

We also note that there is a deficiency in vitamin B12, A, C, E , B16 and folic acid, as well as a deficiency in mineral elements such as iron, calcium and phosphorous,

These results are in agreement with (4), where he indicated that most of the deficiency is in vitamin A, $\mathrm{C}$, iron, calcium and phosphorous. Likewise, smoking increases the required amount of vitamin $\mathrm{C}$ in order to maintain the serum level of this vitamin, so if the amount or serum level of vitamin $\mathrm{C}$ is compared to one person smoker and the other is a non-smoker, we will find that the serum level of the smoker (who smokes more than 20 cigarettes per day) it is about $25 \%$ less than in a nonsmoker, and the effect is more in people who smoke from 20 - 40 cigarettes per day, as it was found that smoking cigarettes works to reduce the absorption of vitamin $\mathrm{C}^{(13)}$. 


\section{Conclusions}

Behavioral symptoms: change in behavior, academic failure, absconding from school, disappearance of drugs from their storage places, repeated loss of valuables. Psychological symptoms: a state of unusual excitement obstructed by complete mental lethargy, obsession with loud music, wakefulness during the night and sleep during the day, disturbance of relations with parents, siblings and relatives. Health and nutritional symptoms: loss of appetite, not following a proper diet, not eating meals regularly, stomach pain and gastric irritation, weak body resistance, low weight below the normal limit, intolerance to stress from overwork, severe red eyes.

\section{Conflict of Interest: None}

\section{Funding: Self}

Ethical Clearance: Not required

\section{References}

1- Ahmed A, Obayan A. Effect of Smoking on Appetite, Concentration and Stress Level, Global journal of health science. 2019. 12(1):139.v12.

2- Cavallo DA, Smith AE, Schepis TS, Desai R, Potenza MN, Krishnan-Sarin S. Smoking expectancies, weight concerns, and dietary behaviors in adolescence. Pediatrics. $2010 \mathrm{Jul}$ 1;126(1):e66-72.

3- Jacobs M. Adolescent smoking: The relationship between cigarette consumption and BMI. Addictive behaviors reports. 2019 Jun 1;9:100153.

4- Chiolero A, Faeh D, Paccaud F, Cornuz J. Consequences of smoking for body weight, body fat distribution, and insulin resistance. The American journal of clinical nutrition. 2008 Apr 1;87(4):8019.

5- Copeland AL, Carney CE. Smoking expectancies as mediators between dietary restraint and disinhibition and smoking in college women. Experimental and clinical psychopharmacology.
2003 Aug;11(3):247.

6- Toschke AM, Ehlin AG, von Kries R, Ekbom A, Montgomery SM. Maternal smoking during pregnancy and appetite control in offspring. Journal of perinatal medicine. 2003 May 14;31(3):251-6.

7- O'Loughlin J, Kishchuk N, DiFranza J, Tremblay M, Paradis G. The hardest thing is the habit: a qualitative investigation of adolescent smokers' experience of nicotine dependence. Nicotine \& Tobacco Research. 2002 May;4(2):201-9.

8- Nu CT, MacLeod P, Barthelemy J. Effects of age and gender on adolescents' food habits and preferences. Food quality and preference. $1996 \mathrm{Jul}$ $1 ; 7(3-4): 251-62$.

9- Pénzes M, Czeglédi E, Balázs P, Foley KL. Factors associated with tobacco smoking and the belief about weight control effect of smoking among Hungarian adolescents. Central European journal of public health. 2012 Mar;20(1):11.

10- Sim WY, Cho YG, Kang JH, Park HA, Kim KW, Im Hur Y, Shin KE, Byeon GR. The relationship between smoking and unhealthy weight control behaviors among Korean adolescents: The tenth Korea youth risk behavior web-based survey, 2014. Korean Journal of Family Medicine. 2017 Jan;38(1):28.

11- Van Minh H, Hai PT, Giang KB, Nga PQ, Khanh PH, Lam NT, Kinh LN. Effects of individual characteristics and school environment on cigarette smoking among students ages 13-15: a multilevel analysis of the 2007 Global Youth Tobacco Survey (GYTS) data from Vietnam. Global Public Health. 2011 Apr 1;6(3):307-19.

12- Whitney EN, Rolfes SR. Understanding Nutrition. $19^{\text {th }}$ edition,wadsworth Group. 2002.

13- French SA, Perry CL, Leon GR, Fulkerson JA. Weight concerns, dieting behavior, and smoking initiation among adolescents: a prospective study. American Journal of Public Health. 1994 Nov;84(11):1818-20. 